\title{
Larval settlement: chemical markers for tracing production, transport, and distribution of a waterborne cue
}

\author{
Patrick J. Krug*, Richard K. Zimmer \\ Department of Biology, University of California, Los Angeles, California 90095-1606, USA
}

\begin{abstract}
Dissolved chemical signals mediate many ecological interactions in the marine environment, but little is known about how rates of production and distribution of waterborne cues affect lifehistory processes in the field. Larvae of the specialist marine herbivore Alderia modesta settle and metamorphose in response to complex carbohydrates produced exclusively by the adult host alga Vaucheria longicaulis, but the natural cue cannot be detected in sea water by current methods of analytical chemistry. The simple carbohydrates mannitol and glucose, which are highly concentrated in $V$. longicaulis tissue, were tested as possible markers for the settlement cue in laboratory and field experiments. In production experiments, both mannitol and glucose were released by patches of the algae and accumulated in the surrounding water over time, as did bioactivity due to the settlement cue. Pore water trapped within patches of $V$. longicaulis during low tides contained high concentrations of mannitol and glucose, and induced a high level of larval metamorphosis even at a 1:5 dilution. The bioactive pore water was released from algal patches into overlying water following immersion by a flood tide; water collected above the surface of $V$. longicaulis induced significant metamorphosis and changes in larval swimming behavior. Glucose content was significantly correlated with bioactivity in water collected above algal mats throughout the first $30 \mathrm{~min}$ of a flood tide, and also $2 \mathrm{~h}$ later, during the peak of a high tide. Mannitol and glucose concentrations were high in sea water above the center of an algal patch, but diminished rapidly at the edges and outside of the patch. Pore water collected from mats of the co-occurring alga Enteromorpha clathrata did not induce metamorphosis or changes in larval swimming behavior, and contained only background levels of the markers. The combined results show that mannitol and glucose are indeed released and transported along with complex carbohydrates from $V$. longicaulis, and can be used to define patterns of distribution of the dissolved settlement cue on both spatial and temporal scales. Ecologically, the data suggest that settlement rates of larvae of $A$. modesta may vary widely during a tidal cycle, as a function of the release and subsequent hydrodynamic transport of waterborne cues from the host alga.
\end{abstract}

KEY WORDS: Larval settlement $\cdot$ Chemical cue $\cdot$ Metamorphosis $\cdot$ Recruitment $\cdot$ Alderia modesta Vaucheria longicaulis

Resale or republication not permitted without written consent of the publisher

\section{INTRODUCTION}

Marine chemical ecology has traditionally focused on the ecological roles of non-polar secondary metabolites, which are generally contained on or within the surface of living tissue (Hay 1996). However, polar molecules can function as waterborne chemical signals, and dissolved cues mediate many interactions in

*E-mail: pkrug@biology.ucla.edu the ocean environment, including predation (ZimmerFaust 1989, Leonard et al. 1999), mating (Gleeson et al. 1984), and habitat selection (Hadfield \& Scheuer 1985, Lambert \& Todd 1994, Krug \& Manzi 1999). The distribution of water-soluble molecules in the field is determined by rates of production and release of the chemicals, followed by transport through advection and molecular or turbulent diffusion (Zimmer \& Butman 2000). To understand the importance of soluble chemical cues to ecological processes, it is thus necessary to 
define the spatial and temporal patterns of waterborne molecules in the field.

Larval recruitment plays a critical role in benthic ecosystems, structuring communities and regulating population dynamics (Grosberg 1982, Roughgarden et al. 1988, Underwood \& Fairweather 1989, Strathmann 1990). Many marine invertebrates produce dispersing larvae that eventually settle to the bottom and metamorphose, often in response to chemical cues of habitat suitability (Grahame \& Branch 1985, Pawlik 1992, Levin \& Bridges 1995). Habitat selection by the larvae of benthic marine invertebrates is often determined by the interaction of signal molecules, hydrodynamics of the natural environment, and larval behavior (Butman 1987, Pawlik et al. 1991, Turner et al. 1994). Recent studies have demonstrated that waterborne signal molecules can trigger changes in larval swimming that can increase rates of settlement under natural flow conditions. For example, larvae of the oyster Crassostrea virginica responded to a dissolved chemical cue by swimming more slowly and turning more frequently in the water column, behavior that increased settlement rates in flowing water (Turner et al. 1994, Tamburri et al. 1996). Larval swimming trajectories were quantified through computer-assisted video motion analysis, demonstrating that larvae stimulated by the soluble cue swam downwards towards the bottom, whereas larvae in control sea water swam upwards towards the surface (Tamburri et al. 1996). To extend the results from laboratory flume studies to the field, larval collectors were engineered to release soluble molecules from acrylamide gel, at a controlled rate which was both theoretically calculated and empirically verified by sampling water above the apparatus; when deployed in the field, collectors releasing an inductive peptide caused significantly higher settlement rates of barnacle cyprids than those releasing non-inductive peptide controls (Browne \& Zimmer unpubl. results). Quantifying the distribution of natural waterborne chemicals is thus the next step for delineating the role of dissolved cues in mediating settlement under field conditions (Eckman et al. 1994).

The specialist marine herbivore Alderia modesta (Lovén, 1844) has several features that make it a useful organism for investigating the distribution and ecological effects of dissolved settlement cues in the field. This opisthobranch mollusc occurs in temperate estuaries, feeding exclusively upon yellow-green algae of the genus Vaucheria (Xanthophyta: Xanthophyceae) (den Hartog \& Swennen 1952, Bleakney \& Bailey 1967 , Trowbridge 1993). Lecithotrophic (non-feeding) larvae of $A$. modesta metamorphose in response to complex carbohydrates produced specifically by the adult host alga V. longicaulis (Krug 1998b, Krug \& Manzi 1999, Krug in press). Water trapped within absorbent mats of the algae during low tides (hereafter termed 'pore water') becomes saturated with the soluble form of the carbohydrate settlement cue; pore water induced immediate changes in larval swimming behavior and triggered metamorphosis, even when diluted 5-fold or more (Krug \& Zimmer 2000). However, previous studies did not examine the flux of dissolved compounds out of algal mats into the surrounding water, where the cue would be substantially diluted by turbulent mixing and advection.

The bioactive oligosaccharides produced by the alga Vaucheria longicaulis exist in a complex mixture varying in composition and molecular weight (Krug 1998a, Krug \& Manzi 1999). The most sensitive method for detection and isolation of carbohydrates is high $\mathrm{pH}$ anion-exchange chromatography with pulsed-amperometric detection (HPAEC-PAD, Dionex Systems). This method has a sub-nanomole detection limit for complex carbohydrates and is relatively robust to salt levels in samples from sea water (Kerhervé et al. 1995). However, most likely due to their polyanionic nature, the bioactive compounds from $V$. longicaulis were found to bind irreversibly to the ion-exchange columns used in HPAEC-PAD; the active carbohydrates could not be detected in sea water samples with existing analytical methods (Krug 1998a). We therefore sought to identify other compounds naturally produced by the algae that could be easily measured in sea water samples, and that could serve as markers for the more complex, bioactive molecules.

Two potential markers were the free sugar alcohol mannitol and the monosaccharide glucose. Mannitol, a primary photosynthetic product of many algae, comprised $1.5 \%$ of Vaucheria longicaulis by dry weight (Krug 1998a). Glucose represented 60\% of the low molecular weight carbohydrate pool of $V$. longicaulis, with no other sugar representing more than $12 \%$ of the carbohydrate mass of the algae (Krug 1998a). Mannitol and glucose were expected to be released into pore water by the algae, along with the bioactive oligosaccharides, in detectable amounts. Our hypothesis was that mannitol and/or glucose would correlate with the presence of bioactivity in the water column, functioning as natural markers for the carbohydrate settlement cues produced by $V$. longicaulis. By tracing the distribution of these markers, we could thus estimate the efflux and distribution of chemical cues from mats of $V$. longicaulis into the overlying water, where the cues could mediate larval settlement in the field.

\section{MATERIALS AND METHODS}

Study site. Field work was conducted in the back of Mission Bay, a shallow estuary located in San Diego, 
California, $21 \mathrm{~km}$ north of the border between the USA and Mexico. For a full description and photographs of the study site, see Levin $(1982,1984)$. The mudflat at this site is exposed to air for at least $5 \mathrm{~h}$ during daily low tides. The exposed surfaces of the mud are colonized year-round by mats of the yellow-green alga Vaucheria longicaulis (Abbott \& Hollenberg 1976). Mats of $V$. longicaulis have a moss-like appearance, forming thick, spongy mats that grow as discrete patches or continuous sheets covering the mud.

Carbohydrate analysis. Carbohydrate markers were quantified by analytical HPAEC-PAD and UV detection at $254 \mathrm{~nm}$, at the Glycobiology Core Facility at the University of California, San Diego. Samples were injected onto a CarboPac MA1 column $(4 \times 250 \mathrm{~mm})$, eluting with $60 \mathrm{mM} \mathrm{NaOH}$ for $5 \mathrm{~min}$, followed by a gradient from 60 to $660 \mathrm{mM} \mathrm{NaOH}$ over $30 \mathrm{~min}$, and ending with a $660 \mathrm{mM} \mathrm{NaOH}$ wash for $5 \mathrm{~min}$. Standard runs using $1 \mathrm{nmol}$ each of mannitol and glucose were done at the beginning and end of each analysis, to calibrate response factors for integration, and to control for changes in retention times over the course of each run. The limit of sensitivity was approximately 100 picomoles of a given sugar per injection; analyses could thus be run for $1 \mu$ Molar solutions without concentration, or $0.1 \mu$ Molar solutions with desalting and concentration prior to analysis.

Pore water trapped within Vaucheria longicaulis mats was analyzed by direct injection of 5 to $50 \mu \mathrm{l}$ of filtered sample onto the HPAEC-PAD column. Sea water collected above algal patches was desalted by pouring $0.5 \mathrm{ml}$ of each sample over a short column of Dowex AG-50+ cation exchange resin $(1 \mathrm{ml})$; neutral material, including carbohydrates, was eluted with $10 \mathrm{ml}$ Milli$\mathrm{Q}$ water and lyophilized. Concentrated samples were then dissolved in 50 to $100 \mu \mathrm{l}$ degassed water and analyzed for mannitol and glucose by HPAEC-PAD. Milli$\mathrm{Q}$ water was processed in parallel as a control for the desalting procedure.

Carbohydrate markers in pore water from algal mats. Patches were sampled in the field to determine the variability in carbohydrate marker content between mats of Vaucheria longicaulis. The algae forms absorbent mats that trap water, which becomes highly bioactive over the course of a low tide (Krug \& Zimmer 2000). Initially, pore water was collected from 4 different mats during the final hour of a low tide (October 1999). Gentle pressure was applied to the algal mat, and exuded water was aspirated from the surface of the algae, filtered to $0.22 \mu \mathrm{m}$, and frozen prior to chemical analysis and bioassays. Each sample was analyzed for mannitol and glucose by directly injecting $10 \mu \mathrm{l}$ onto a CarboPac HPAEC-PAD column. Field-collected pore water was diluted to $20 \%$ with filtered sea water (FSW) for use in larval bioassays, as prior results had indicated pore water bioactivity was highly concentrated (Krug \& Zimmer 2000). A further 8 patches were sampled and tested for mannitol and glucose during the final hour of a low tide (January 2000). All pore water collections were made within a 20 min period, and each patch was at least $5 \mathrm{~m}$ distant from all other surveyed algal mats. The density of algal mats was appreciably lower in January 2000; the sampled mats contained much less pore water than in October 1999, and insufficient water was collected to permit testing in metamorphosis bioassays. The 8 samples from January 2000 were therefore tested for marker content only, by directly injecting $50 \mu$ l onto a CarboPac HPAECPAD column.

Marker content was determined over time from a single patch to determine whether there was a detectable increase in concentration of carbohydrates during the course of a low tide. Water from within a patch of algae was sampled $1 \mathrm{~h}$ after the algae was exposed to air by receding waters of an ebb tide, and again immediately before the algae was immersed by the flood tide, after approximately $5 \mathrm{~h}$ exposure to air. Aliquots were tested for marker content by direct injection of $10 \mu$ l onto a CarboPac HPAEC-PAD column. Water samples were diluted to $20 \%$ with FSW prior to use in larval metamorphosis bioassays.

Larval metamorphosis assay. Water samples were tested for bioactivity using a modified form of a previously described larval metamorphosis assay (Krug \& Manzi 1999). Adult specimens of Alderia modesta were collected from the field and held in petri dishes under $1 \mathrm{~cm}$ of sea water in the laboratory overnight. Lecithotrophic egg masses were harvested the following morning and were transferred to plastic dishes containing $0.45 \mu \mathrm{m}$ FSW; water was changed every other day until hatching. Upon hatching, larvae were maintained in FSW for $2 \mathrm{~d}$ and were then subsampled for use in the bioassay. For each experimental treatment, 15 larvae were added to replicate assay dishes containing $4 \mathrm{ml}$ of a given sea water sample. Larvae were scored for metamorphosis after $3 \mathrm{~d}$. Each experiment included a FSW-only treatment as a negative control and live Vaucheria longicaulis as a positive control. The percentage of metamorphosis for each replicate was arcsine transformed to normalize the data. Bartlett's test for homogeneity of variances was used to test for heteroscedasticity in each data set; $t^{\prime}$ $t$-tests with a Bonferroni adjustment and an overall significance level of $5 \%$ were used for multiple comparisons when variances between treatments were significantly different, or for increased sensitivity over the more conservative post-hoc Scheffé test (Snedecor \& Cochran 1980). Treatments with homogenous variances were compared using a 1-way ANOVA (Sokal \& Rohlf 1981). Unplanned comparisons of means were 
done using the Scheff procedure when the $F$-ratio was significant (Day \& Quinn 1989).

Rates of production and release of markers and bioactivity in the laboratory. The release of (1) bioactive compounds and (2) the carbohydrate markers mannitol and glucose was measured from small patches of Vaucheria longicaulis in laboratory experiments. Mats of algae attached to the natural sediment base $\left(5 \mathrm{~cm}^{2}\right)$ were collected from the field and maintained in an incubator held at $18^{\circ} \mathrm{C}$ on a $16: 8 \mathrm{~h}$ light:dark cycle. Algae was moistened daily with sea water. In a preliminary experiment, 1 mat was submerged in sea water and stirred for $30 \mathrm{~min}$. Small patches of $V$. longicaulis measuring $1 \times 1 \mathrm{~cm}$ were then cut from the mat with a razor blade, slicing immediately below the point of attachment of basal filaments of the algae to the underlying sediment. Patches were placed in $4 \mathrm{ml}$ FSW in plastic assay dishes for the following time intervals: $10 \mathrm{~s}, 1,5,10$, and $20 \mathrm{~min}$. At the end of a given time, patches were removed by sterile forceps and pressed gently against the side of the dish to remove trapped water. Three replicates were done for each time interval. The $V$. longicaulis-conditioned water in each dish was filtered to $0.22 \mu \mathrm{m}$ and tested in the larval metamorphosis bioassay. The relationship between the time algae was bathed in sea water and the percentage of metamorphosis induced in the larval bioassay was estimated using a Model 1 regression; percentages of metamorphosis were arcsine transformed prior to analysis.

A subsequent experiment was run to quantify the release of both bioactivity and carbohydrate markers over shorter time periods in the laboratory. Small patches of algae were cut from an algal mat, as described above, and incubated for varying time periods in 3 separate trials, yielding the same pattern in each case. Results are presented for the trial in which patches were placed in $15 \mathrm{ml}$ FSW in glass dishes for the following time intervals: $1,2.5,5,7.5$, and $10 \mathrm{~min}$. Patches were removed after the allotted time as before, and were then blotted dry. Three replicate patches were used for each time interval. Patches of sediment without Vaucheria longicaulis were also cut from the mud and were incubated in sea water for $10 \mathrm{~min}$, as controls for any carbohydrate content of the sediment base. One aliquot of conditioned sea water $(1 \mathrm{ml})$ was removed from each dish for chemical analysis to quantify mannitol and glucose content. A second aliquot $(4 \mathrm{ml})$ was removed from each dish, filtered to $0.22 \mu \mathrm{m}$, and tested for bioactivity using the larval metamorphosis assay. Patches were lyophilized and weighed after the experiment to quantify release of carbohydrates as a function of both mass of algae and time. The release rate of markers was ultimately calculated as micromoles of mannitol and nanomoles of glucose produced per gram of algae. The relationship between (1) the timed duration over which algae was incubated in sea water and (2) $\mu \mathrm{mol}$ or nmol of carbohydrate marker released per gram of algae was estimated using a Model 1 regression for both mannitol and glucose. A Model 1 regression was also used to compare the bioactivity of water samples from the different timed exposures, using arsine-transformed percentages of metamorphosis. Water exposed to mud for 10 min was used as a negative control for both bioactivity and release of carbohydrate markers.

Time course of release of markers and bioactivity during a flood tide. Based on the preceding results, the release of bioactivity and markers from algal pore water into the water column was measured during the initial immersion of algal patches during a flood tide (October 1999). A sample of pore water was collected from within one representative patch of Vaucheria longicaulis immediately prior to inundation by the rising water. The initial sample from the water column was drawn as soon as the rising tide covered the algae to a depth of $2 \mathrm{~mm}$ (termed 'time $\left.0^{\prime}\right)$. Samples $(60 \mathrm{ml}$ ) were subsequently collected at 5 min intervals, by slowly drawing sea water through a 20 -gauge needle into a syringe from a height of $2 \mathrm{~mm}$ above the algal patch. The syringe was mounted on a ruler, such that the tip of the needle was fixed at a height of $2 \mathrm{~mm}$ above the bottom edge of the ruler, which was rested on the surface of the algal mat for sampling. A control sample of Mission Bay water was collected from the low water mark, over an area of mudflat $50 \mathrm{~m}$ distant from the nearest $V$. longicaulis, to represent water that larvae in the bay would encounter prior to tidal inundation of the high mudflat and $V$. longicaulis mats. Samples were filtered to $0.22 \mu \mathrm{m}$ and frozen at $-80^{\circ} \mathrm{C}$ prior to use in bioassays. Carbohydrate marker content was determined as described above, by desalting and concentrating samples 5 -fold. Water samples were tested in the larval metamorphosis assay and in the behavioral assay, to measure (1) induction of metamorphosis and (2) rate of change in direction (RCD).

For statistical analysis, percentages of metamorphosis were arcsine transformed to normalize the data. Multiple comparisons were performed for time 0 and 5 min water samples against all subsequent time points, using a $t^{\prime} t$-test with a Bonferroni adjustment and an overall significance level of $5 \%$ (Snedecor \& Cochran 1980). This method was sensitive to differences between the 5 min sample and subsequent time points, compared with the more conservative post-hoc Scheffé test. RCD data were normally distributed and were compared directly using a 1-way ANOVA. For water taken at each time point, Spearman rank correlation analyses were used to test for a relationship between glucose content and (1) percent metamorpho- 
sis or (2) RCD of larval swimming paths. A nonparametric correlation test was used to avoid biasing the analysis by extreme values from the initial time point.

Larval swimming behavior assay. The swimming behavior of larvae was recorded using a Cohu infrared-sensitive video camera with a Pentax $100 \mathrm{~mm}$ macro lens. All video recording was carried out at $22^{\circ} \mathrm{C}$, in a darkroom using only infrared light. Larvae were filmed while swimming $\leq 1 \mathrm{~mm}$ above the bottom of a round chamber made of a Plexiglas cylinder with a $32 \mathrm{~mm}$ internal diameter. The chamber was rested on a clear Plexiglas sheet with the camera set up beneath. Video recordings were processed at 10 frames $\mathrm{s}^{-1}$ through a computer-assisted video motion analyzer (Motion Analysis Corp. model VP 320 and ExpertVision software) interfaced with a Sun Microsystems SPARC 2 computer workstation. Lecithotrophic larvae (15 replicate $^{-1}$ ) were placed in $5 \mathrm{ml}$ of FSW (negative control) or a sample of sea water collected from the field, and after a $5 \mathrm{~s}$ delay, larval behavior was filmed for $1 \mathrm{~min}$. For each treatment and control, 10 to 12 replicates were run, and all larval paths were recorded and analyzed. Angular velocity (measured as RCD) and swimming speed were quantified for all larval paths during each filmed treatment. Differences in mean values for all paths from treatments and controls were compared using a 1-way ANOVA with a post-hoc Scheffé test for unplanned comparisons of means. Data are given in the text as means $\pm \mathrm{SE}$.

Spatial distribution of markers above a patch of Vaucheria longicaulis. Water was sampled $2 \mathrm{~mm}$ above the surface of Vaucheria longicaulis at various distances from the center of a roughly circular patch, $16 \mathrm{~mm}$ in diameter, to determine spatial distribution of the markers. Nine segments of Teflon tubing $(0.5 \mathrm{~m}$ length) were used to draw water into sterile syringes. One end of each length of tubing was mounted on a wooden plank, with the tip of the tubing protruding $5 \mathrm{~mm}$ over the edge of the plank. The end of one length of tubing was mounted in the center of the plank, and the ends of the remaining 8 pieces of tubing were positioned 2,4,8, and $16 \mathrm{~mm}$ to the left and right of the center. The other end of each piece of tubing was attached to a needle secured onto a separate luer-lock syringe. The plank was placed over the top of a patch of $V$. longicaulis at low tide, such that the tips of the tubing were positioned $2 \mathrm{~mm}$ above the dry surface of the algal mat. Both ends of the plank were rested on elevated areas of the mud surface, such that the plank itself was above the surface of the patch and out of the water at all times. When the rising water of the next flood tide had immersed the algae to a depth of $2 \mathrm{~mm}$, $5 \mathrm{ml}$ of water was slowly drawn into each syringe.
Samples were transferred from syringes to sterile centrifuge tubes, and were then filtered to $0.22 \mu \mathrm{m}$ and frozen at $-80^{\circ} \mathrm{C}$ prior to analysis. An aliquot of each sample $(0.5 \mathrm{ml})$ was desalted and analyzed for mannitol and glucose content as described above.

Correlation of markers and bioactivity in water collected during a high tide. To determine whether the cue was present above algal patches during subsequent hours of a high tide, sea water was collected above each of 8 different patches of Vaucheria longicaulis during the peak of a high tide. The 8 mats of algae were randomly selected, and each patch was at least $2 \mathrm{~m}$ distant from the nearest sampled patch. Samples were collected by syringe through a 20-gauge needle from a height of $2 \mathrm{~mm}$ above the surface of the algae, $2 \mathrm{~h}$ after tidal immersion when water depth was $\sim 50 \mathrm{~cm}$ above patches of $V$. longicaulis. A control sample of sea water was collected from Mission Bay during a low tide, from an area of mudflat $50 \mathrm{~m}$ distant from any patches of $V$. longicaulis. Bioactivity was measured by adding larvae directly to replicate assay dishes containing the 8 water samples filtered to $0.22 \mu \mathrm{m}$. Glucose content was measured for each sample of field-collected water, and a Spearman rank correlation analysis was used to test for a relationship between glucose concentration and the percent metamorphosis induced by each water sample.

Specificity of markers and bioactivity in Vaucheria longicaulis pore water. The only macroalgal species that commonly co-occurs with Vaucheria longicaulis at the Mission Bay field site is the filamentous green alga Enteromorpha clathrata (Krug in press). To determine whether the carbohydrate markers and bioactivity were specific to water conditioned by $V$. longicaulis, water samples were collected from a small pool containing a dense, filamentous mat of E. clathrata. This E. clathrata pore water was filtered to $0.22 \mu \mathrm{m}$ and frozen at $-80^{\circ} \mathrm{C}$ prior to analysis. Mannitol and glucose content were measured by desalting and concentrating $0.5 \mathrm{ml}$ of E. clathrata pore water followed by HPAECPAD analysis. Bioactivity was measured (1) in the larval metamorphosis assay, by adding larvae directly to replicate dishes containing filtered pore water, and (2) in the behavioral assay, by recording larval swimming in pore water. Results were compared with the sample of sea water collected $2 \mathrm{~mm}$ above a patch of $V$. longicaulis immediately upon tidal immersion ('time 0 ' sample) and with filtered sea water controls, using a 1-way ANOVA with a post-hoc Scheffé test. A second collection of E. clathrata-conditioned sea water was made by compressing mats of E. clathrata in the field, and collecting the algal exudate. This water sample was only analyzed for carbohydrate markers, as the high organic content led to microbial contamination in metamorphosis assays. 


\section{RESULTS}

\section{Carbohydrate markers in pore water from algal mats}

The free sugar alcohol mannitol and the monosaccharide glucose are the primary low molecular weight carbohydrates in the tissue of Vaucheria longicaulis. To determine whether these 2 compounds could be used as detectable markers for complex carbohydrates produced and released by $V$. longicaulis into sea water, we collected samples of sea water from within the spongy mats of $V$. longicaulis during low tide in the field. These samples of 'pore water' were then analyzed for mannitol and glucose content by analytical chromatography using HPAEC-PAD. In preliminary assays, both mannitol and glucose were detected in pore water samples at $\mu \mathrm{M}$ concentrations (Table 1). It was not necessary to concentrate or desalt pore water prior to analysis for detection of these compounds. The background concentrations of both molecules in Mission Bay water were below the limit of detection $(<100$ pmol of carbohydrate per injection) when a comparable volume of water was analyzed directly by HPAEC-PAD.

Variation in concentration of the markers between patches of Vaucheria longicaulis was measured by sampling 4 mats in October 1999 and an additional 8 mats in January 2000. High levels of both mannitol and glucose were measured in all 4 pore water samples taken in October 1999 (Table 1). A 2-fold difference in

Table 1. Carbohydrate analysis of pore water collected from within patches of Vaucheria longicaulis. Samples of sea water were initially collected from 4 mats in October 1999; an additional 8 mats were sampled in January 2000. All samples were filtered to $0.22 \mu \mathrm{m}$ and frozen prior to analysis. An aliquot (10 to $50 \mu \mathrm{l}$ ) of each sample was injected directly onto an HPAECPAD column with no prior desalting; a second injection at a different volume was used to confirm each result. Because pore water was not concentrated before analysis, markers were below the sensitivity limit for some samples (nd $=$ not detected)

\begin{tabular}{|lcc|}
\hline Algal patch & Mannitol $(\mu \mathrm{M})$ & Glucose $(\mu \mathrm{M})$ \\
\hline October 1999 & & \\
1 & 392 & 82 \\
2 & 372 & 80 \\
3 & 782 & 186 \\
4 & 732 & 200 \\
January 2000 & & \\
5 & nd & nd \\
6 & nd & nd \\
7 & 9.8 & 8.2 \\
8 & 31.0 & 2.4 \\
9 & 17.2 & 5.8 \\
10 & 19.2 & nd \\
11 & nd & 2.6 \\
12 & 14.4 & \\
\hline
\end{tabular}

concentration was found between mats with the highest and lowest marker content. In contrast, the mean abundance of both markers was approximately 50 -fold lower in pore water collected in January 2000 (Table 1). The thickness of $V$. longicaulis mats varies seasonally at the Mission Bay study site, and the density of algal patches was much lower in January 2000. Markers were only detected in 5 of 8 samples by direct injection of pore water onto the HPAEC-PAD column; however, pore water was not desalted and concentrated, which would have permitted the detection of lower levels of each marker. The concentration of mannitol decreased significantly from a mean of $570 \pm$ $109 \mu \mathrm{M}$ SE in October 1999 to a mean of $11 \pm 4 \mu \mathrm{M} \mathrm{SE}$ in January 2000 (unpaired 2-tailed $t$-test: $\mathrm{df}=10, t=$ $7.6, \mathrm{p}<0.0001)$. The mean concentration of glucose also decreased significantly between October (137 \pm $32 \mu \mathrm{M} \mathrm{SE})$ and January $(3 \pm 1 \mu \mathrm{M} \mathrm{SE}$ ) (unpaired 2 -tailed $t$-test: $\mathrm{df}=10, t=6.1, \mathrm{p}<0.0001$ ). Although the concentration of each marker decreased significantly between the October and January samples, the mean ratio of mannitol to glucose in pore water remained consistent. There was no significant difference in the mean ratio of mannitol to glucose in pore water from October 1999 (mean ratio $=4.32, \mathrm{n}=4$ mats) and January 2000 (mean ratio $=4.35, \mathrm{n}=5$ mats).

A single collection of pore water was previously shown to induce high levels of metamorphosis when tested at field strength. To test for between-patch variation in bioactivity, pore water was collected from 4 different mats of Vaucheria longicaulis. Each sample was assayed for induction of larval metamorphosis at a 1:5 dilution of the field concentration, and compared with background water from Mission Bay. All samples of 1:5-diluted pore water induced significantly higher levels of metamorphosis than did Mission Bay water (Fig. 1, and results of a 1-way ANOVA: $F_{4,14}=9.43, \mathrm{p}=$ $0.0006)$. There was no significant difference in bioactivity between pore water from any of the 4 patches (Fig. 1).

To determine whether the concentration of markers increased in pore water over the course of a low tide, samples were collected from one algal mat after the algae had been exposed to air for $1 \mathrm{~h}$, and again from the same mat $4 \mathrm{~h}$ later, immediately before tidal inundation of the algal mats. A detectable increase was found in the pore water concentration of both mannitol and glucose over the $4 \mathrm{~h}$ sampling interval (Table 2). The concentration of glucose was found to double during the course of the low tide, while mannitol showed a clear but less dramatic increase. The percentage of metamorphosis induced by 1:5-diluted water did not change significantly over the course of the low tide, due to the high activity of pore water after the tide had initially receded. 


\section{Production and release of markers and bioactivity in the laboratory}

The production and release of both markers and bioactivity were quantified in the laboratory for small patches of Vaucheria longicaulis. When mats of the algae were immersed in sea water, both mannitol and glucose were released into the surrounding water and

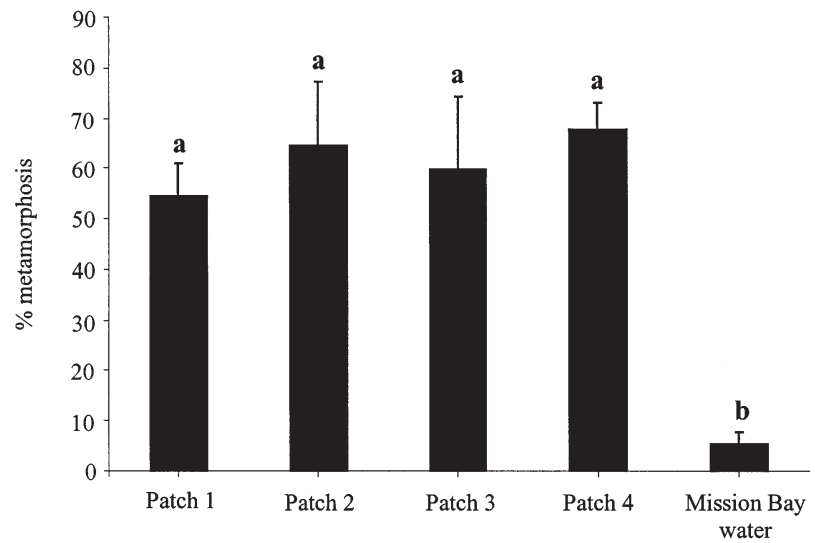

Fig. 1. Induction of larval metamorphosis of Alderia modesta by diluted pore water from patches of the alga Vaucheria longicaulis. Pore water trapped within spongy mats of $V$. longicaulis was collected from 4 different patches of the alga during a low tide, when the algae was exposed to air. Pore water was diluted 1:5 with filtered sea water and bioassayed for induction of metamorphosis using lecithotrophic larvae of A. modesta. Water collected from an area of Mission Bay devoid of $V$. longicaulis was used as a negative control. Data are mean $(+\mathrm{SE})$ percentages of metamorphosis. Means marked with the same letter did not differ significantly (1-way ANOVA on arcsine-transformed percentages, followed by a post-hoc Scheffé test for unplanned multiple comparisons)

Table 2. Accumulation of carbohydrate markers and bioactivity in pore water over the course of a low tide. Samples of pore water were collected from within one patch of Vaucheria longicaulis $1 \mathrm{~h}$ after exposure to air on a receding tide, and $4 \mathrm{~h}$ later, immediately prior to immersion on the flood tide. An aliquot (10 to $50 \mu \mathrm{l}$ ) of each sample was injected directly onto an HPAEC-PAD column with no prior desalting to quantify mannitol and glucose concentration. Aliquots were diluted to $20 \%$ field strength with filtered sea water and used in the larval metamorphosis bioassay to test for changes in bioactivity, expressed as percent metamorphosis $\pm \mathrm{SE}(\mathrm{n}=3)$, over the low tide

\begin{tabular}{|lccc|}
\hline $\begin{array}{l}\text { Time } \\
\text { sampled }\end{array}$ & $\begin{array}{c}\text { Mannitol } \\
(\mu \mathrm{M})\end{array}$ & $\begin{array}{c}\text { Glucose } \\
(\mu \mathrm{M})\end{array}$ & $\begin{array}{c}\text { Bioactivity } \\
(\%)\end{array}$ \\
\hline $\begin{array}{l}\text { Initial exposure } \\
\text { to air (slack tide) }\end{array}$ & 312 & 38 & $59.2 \pm 2.6$ \\
$\begin{array}{l}4 \text { h later } \\
\text { (before flood tide) }\end{array}$ & 372 & 80 & $67.7 \pm 5.5$ \\
\hline
\end{tabular}

accumulated over time (Fig. 2). The relationship between immersion time and release of mannitol and glucose was estimated to determine whether markers increased in concentration with time. Time of immer-
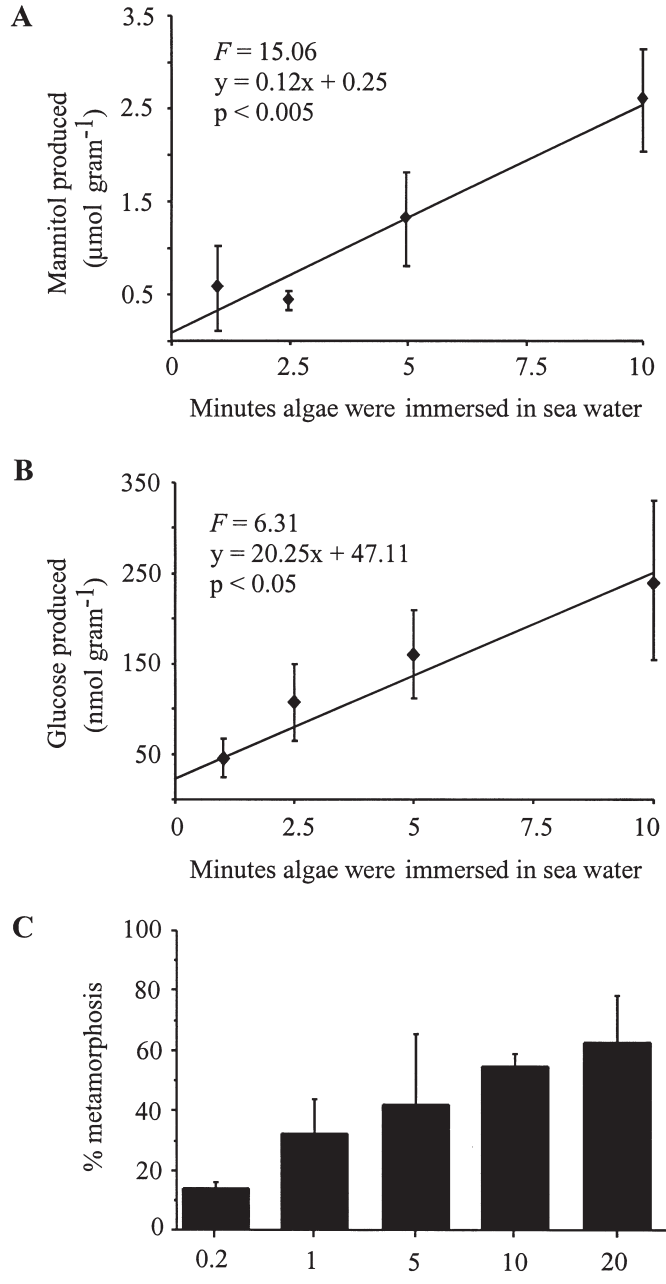

Minutes algae were immersed in sea water

Fig. 2. Laboratory production and release of carbohydrate markers and bioactivity from small patches of Vaucheria longicaulis. Replicate patches of algae $(\mathrm{n}=3)$ were immersed in filtered sea water for timed intervals. The concentration of both markers and the bioactivity of the resulting solutions were then determined, and algal patches were dried and weighed. (A) Production of mannitol by V. longicaulis. Data are given as mean $( \pm \mathrm{SE}) \mu \mathrm{mol}$ of mannitol produced per gram of algal patch (dry weight) in the indicated amount of time, plotted with the results of a linear regression. (B) Production of glucose by $V$. longicaulis. Data are given as mean $( \pm \mathrm{SE})$ nmol of glucose produced per gram of algal patch (dry weight) in the indicated amount of time, plotted with the results of a linear regression. (C) Release of bioactivity by $V$. longicaulis. Sea water was conditioned by patches of the alga for the indicated time interval, and was then filtered to $0.22 \mu \mathrm{m}$. Larvae of Alderia modesta (15 per replicate dish) were added to the $V$. longicaulis-conditioned water and were scored for metamorphosis after $3 \mathrm{~d}$. Data are mean $(+\mathrm{SE})$ percentages of metamorphosis 
sion accounted for a significant percentage of the variance in mannitol content of conditioned sea water (Fig. 2A, and results of a Model 1 regression of effects of time, $x$, on mannitol release, $y: y=0.12 x+0.25 ; F_{1,11}$ $\left.=15.06, \mathrm{p}<0.005, \mathrm{r}^{2}=0.60\right)$ and a significant but lower percentage for glucose (Fig. 2B, and results of a Model 1 regression: $y=20.25 x+47.11 ; F_{1,11}=6.31, p<0.05$, $\mathrm{r}^{2}=0.41$ ). After $5 \mathrm{~min}$ of immersion, a mean $1.3 \mu \mathrm{g}$ of

A

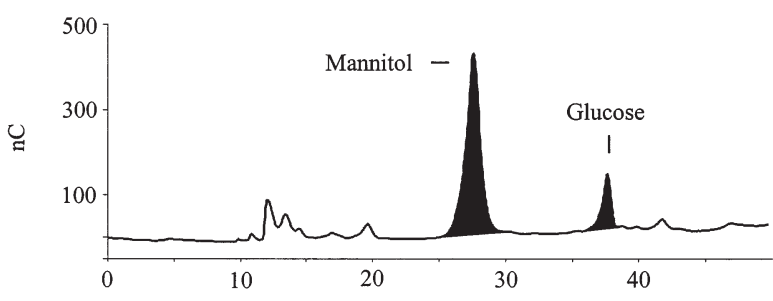

B

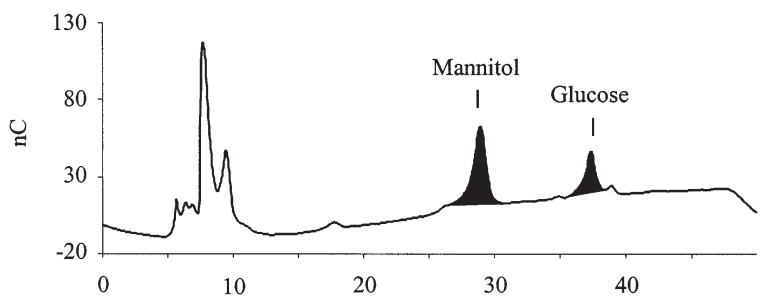

C

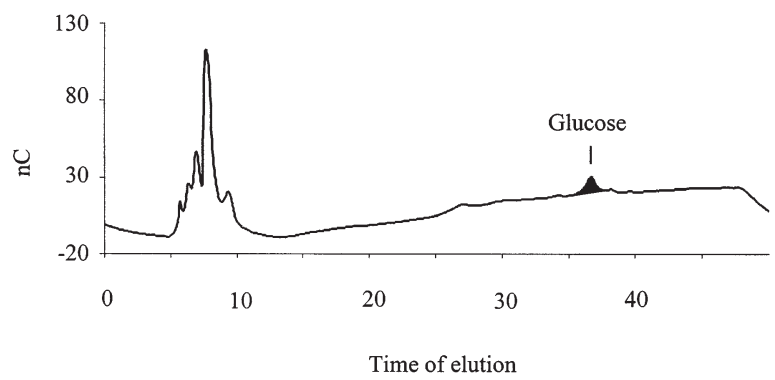

Fig. 3. Carbohydrate analysis of sea water samples using high-pH anion exchange chromatography with pulsedamperometric detection (HPAEC-PAD). Carbohydrates were eluted from an HPAEC-PAD column using a gradient of $\mathrm{NaOH}$ over a 40 min run with electrochemical post-column detection. Units on the $y$-axis are arbitrary absorption units given as nano-coulombs. (A) Carbohydrate marker content of pore water collected within a patch of Vaucheria longicaulis during a low tide. Presence of mannitol and glucose was detected by direct injection of pore water without concentrating the sample. (B) Marker content of water sampled $2 \mathrm{~mm}$ above the same patch of $V$. longicaulis immediately after the rising tide covered the patch to a depth of $2 \mathrm{~mm}$. The water sample was desalted and concentrated 5-fold prior to analysis. Note the change in scale of the $y$-axis compared with (A). (C) Marker content of water sampled $2 \mathrm{~mm}$ above the same patch 10 min after initial tidal immersion. This sample was also concentrated 5-fold prior to analysis mannitol was released per gram of $V$. longicaulis; after $10 \mathrm{~min}$, the amount had doubled to a mean $2.6 \mu \mathrm{g}$ of mannitol per gram of $V$. longicaulis. Time of immersion also accounted for a significant percentage of the variance in bioactivity of $V$. longicaulis-conditioned sea water produced in 2 separate trials (Fig. 2C, and results of a Model 1 regression: $y=0.31 x+0.06 ; F_{1,13}=$ $\left.24.08, \mathrm{p}<0.0005, \mathrm{r}^{2}=0.65\right)$. Neither mannitol nor glucose was released by control patches of mud with the overlying mat of $V$. longicaulis removed, and water conditioned by mud alone had no significant bioactivity. The same general pattern was observed with different patches of $V$. longicaulis collected from the field at different times, indicating that different mats consistently release both markers and bioactivity into the surrounding water over time.

\section{Time course of release of markers and bioactivity during a flood tide}

The preceding results indicated that mannitol, glucose, and the more complex bioactive carbohydrates were produced and released by absorbent mats of Vaucheria longicaulis in the field, and that markers and bioactivity accumulated over time in pore water in both field and laboratory experiments. We therefore hypothesized that during a low tide markers and bioactivity would accumulate in pore water, and would subsequently be released in a concentrated pulse into overlying waters following immersion on the next flood tide. To test this prediction, we sampled water $2 \mathrm{~mm}$ above the surface of a representative mat of $V$. longicaulis immediately upon immersion by a flood tide, and at $5 \mathrm{~min}$ intervals for the next $30 \mathrm{~min}$. Water samples were bioassayed for (1) induction of larval metamorphosis, (2) induction of changes in larval swimming behavior, and (3) concentration of mannitol and glucose. Both mannitol and glucose were present in high concentrations in the pore water prior to immersion by the flood tide (Fig. 3A). When the rising water had covered the $V$. longicaulis mat to a depth of $2 \mathrm{~mm}$ (time 0 ), both markers were detectable in the water column $2 \mathrm{~mm}$ above the surface of the algae (Fig. 3B). After $10 \mathrm{~min}$, only glucose was detectable in the water column, at a significantly reduced concentration (Fig. 3C); glucose was detectable in all water samples taken over the first $30 \mathrm{~min}$ following tidal inundation. In subsequent analyses, we therefore focused on glucose as a natural marker, and tested for correlations between glucose concentration and bioactivity of water samples taken above $V$. longicaulis patches.

Water samples collected above the algal mat at sequential 5 min intervals differed significantly in the percentage of metamorphosis induced in larval bioas- 
says (Fig. 4A). Water collected at time 0 (when water first reached a depth of $2 \mathrm{~mm}$ ) induced a significantly higher mean level of metamorphosis (58.2 $\pm 9.4 \% \mathrm{SE})$ than all water samples collected after the 5 min time point ( $t^{\prime} t$-test with a Bonferroni correction, $\left.\mathrm{p}<0.05\right)$. The 5 min water sample also stimulated significantly higher metamorphosis than the 30 min water sample and control Mission Bay water ( $t^{\prime} t$-test with a Bonferroni correction, $\mathrm{p}<0.05)$. Most bioactivity was therefore released in a concentrated burst during the initial immersion, and was rapidly diluted by rising water after the first $5 \mathrm{~min}$ of the flood tide.

Vaucheria longicaulis pore water induced changes in larval swimming behavior, causing larvae to turn with increased frequency in response to the dissolved settlement cue (Krug \& Zimmer 2000). However, larval response to water collected above algal patches was not previously tested. We therefore analyzed larval swimming behavior in response to the water samples collected at $5 \mathrm{~min}$ intervals above the $V$. longicaulis patch. Motion analysis revealed significant variation in larval behavior, quantified as RCD (Fig. 4B, and results of a 1 -way ANOVA: $\left.F_{4,271}=6.36, \mathrm{p}<0.0001\right)$. The initial water sample induced the highest RCD, which was significantly greater than the turning rate induced by the 30 min sample and background bay water (Scheffé test, $\mathrm{p}<0.05)$. Water sampled at $10 \mathrm{~min}$ after submersion still induced a significantly higher RCD than background bay water (Scheffé test, $\mathrm{p}<0.05$ ). Over the

Fig. 4. Bioactivity and carbohydrate marker content of sea water sampled $2 \mathrm{~mm}$ above a patch of Vaucheria longicaulis in the field. Water was collected beginning at the time of initial immersion of the patch (time 0 ) by a flood tide, and at subsequent 5 min intervals for the next $30 \mathrm{~min}$. (A) Bioactivity of water collected in the field above a patch of $V$. longicaulis. Lecithotrophic larvae of Alderia modesta $\left(15\right.$ dish $\left.^{-1}\right)$ were added to water samples in replicate dishes $(n=6$ replicate dishes per time point). Data are mean $(+\mathrm{SE})$ percentages of larval metamorphosis after $3 \mathrm{~d}$ exposure to the sea water sample. Percentages were arcsine transformed and compared using a $t^{\prime} t$-test with a Bonferroni correction for multiple comparisons and an overall significance level of $5 \%\left({ }^{*} \mathrm{p}<0.05\right.$ compared with sea water controls). (B) Behavioral response of larvae of $A$. modesta to sea water sampled above a patch of $V$. longicaulis. Rate of change in direction (RCD) was quantified using computer-assisted video motion analysis for lecithotrophic larvae in response to field-collected water samples and background Mission Bay water. Data are mean (+SE) RCD for all larval paths recorded for a given treatment. Means marked with the same letter did not differ significantly (1-way ANOVA on arcsine-transformed percentages, followed by a post-hoc Scheffé test for unplanned multiple comparisons). (C) Glucose content of water samples collected above a patch of $V$. longicaulis. Water samples were concentrated 5-fold and analyzed for carbohydrate content by analytical HPAEC-PAD. Data are plotted with the results of a logarithmic function showing the exponential decay of glucose concentration over time first $30 \mathrm{~min}$ of the flood tide, water sampled at each successive time point induced progressively lower RCD values in larvae. The behavioral and metamorphosis bioassay data therefore show the same trend, with a spike in bioactivity at time 0 that progressively diminished to background levels over time. The percent metamorphosis and RCD induced by field water samples were significantly correlated (Spearman's rank correlation: $\rho=0.89, Z=1.98, p<0.05)$. There was no change between treatments in larval swimming speed $(F=1.33, \mathrm{p}>0.25)$, which is less sensitive to the presence of the $V$. longicaulis-associated chemical cue than RCD (Krug \& Zimmer 2000).

The glucose content of the bioassayed water samples was determined, and showed a dramatic pulse of the marker out of the patch at time 0 , followed by an exponential decay of the marker until background levels of bay water $(0.1 \mu \mathrm{M})$ were reached at the $30 \mathrm{~min}$ time point (Fig. 4C). The concentration of glucose in water samples was significantly correlated with the percent-
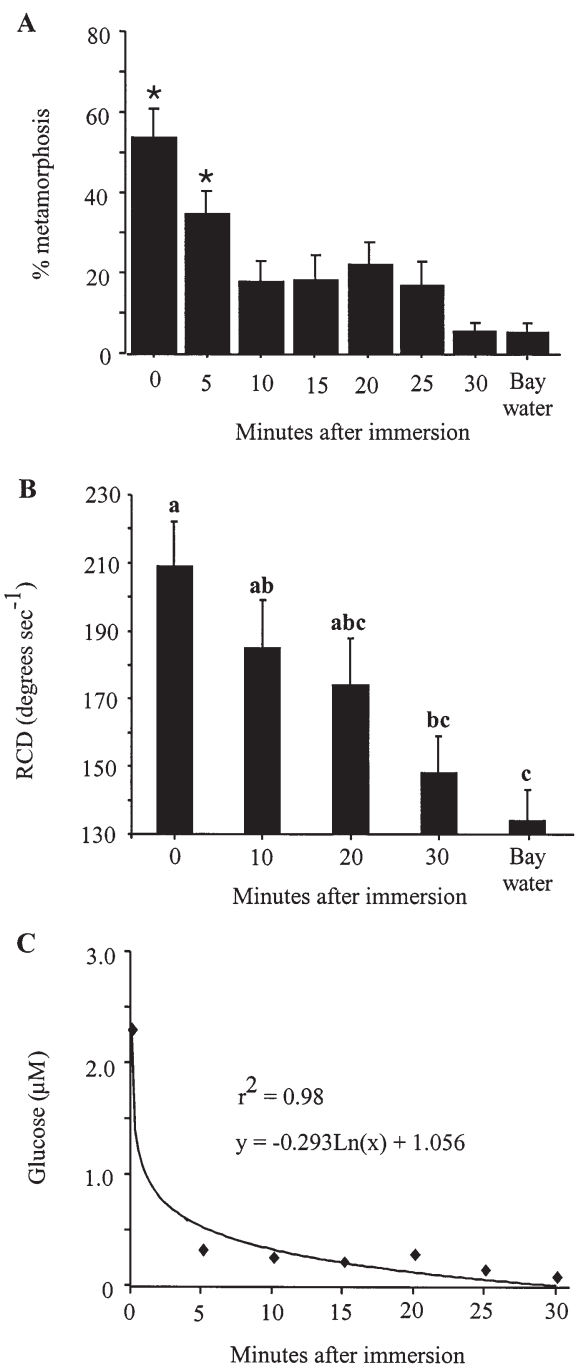


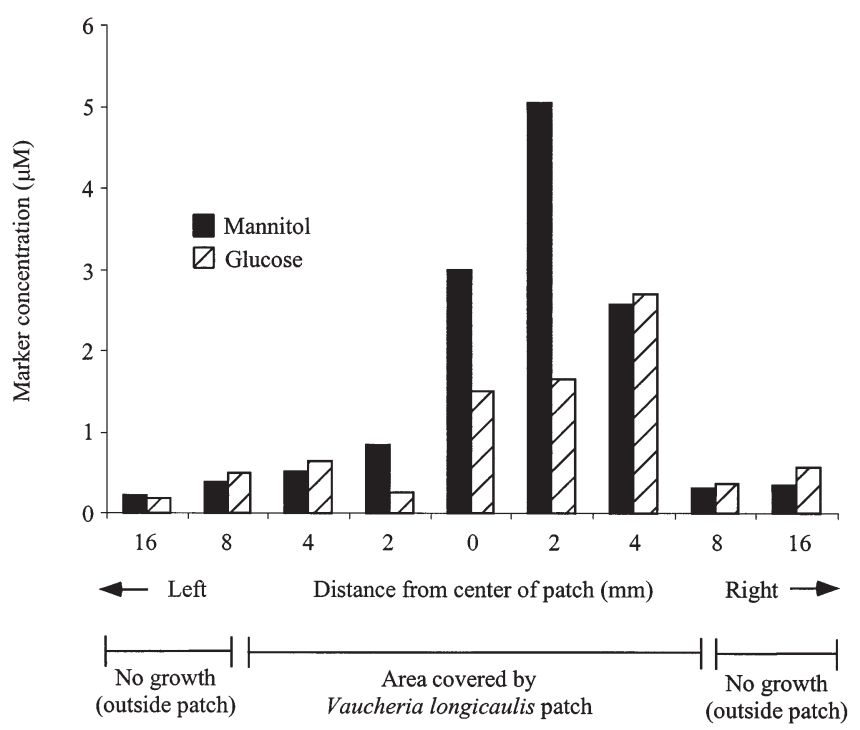

Fig. 5. Spatial distribution of carbohydrate markers above and around a patch of Vaucheria longicaulis. Marker content of water was measured $2 \mathrm{~mm}$ above the bottom immediately following immersion by a flood tide, at various distances from the center of a patch of $V$. longicaulis. The patch extended $8 \mathrm{~mm}$ to the left and right of the center point; water sampled $16 \mathrm{~mm}$ from the center was above uncolonized mud. Data are concentrations of mannitol and glucose measured by analytical HPAEC-PAD

age of metamorphosis induced in larval bioassays (Spearman's rank correlation: $\rho=0.98, Z=2.58, \mathrm{p}<$ $0.01)$. The correlation was significant even if the data for the water sampled at time 0 were omitted from the analysis. Glucose was also significantly correlated with changes in larval swimming behavior, quantified as increased RCD (Spearman's rank correlation: $\rho=0.89$, $Z=1.98, \mathrm{p}<0.05)$.

\section{Spatial distribution of markers above a patch of Vaucheria Iongicaulis}

When water was sampled $2 \mathrm{~mm}$ above the surface of a patch of Vaucheria longicaulis in March 2000, both markers were again present at high concentrations over the center of the patch immediately following tidal immersion (Fig. 5). Marker concentrations were highest in water collected within 2 to $4 \mathrm{~mm}$ of the center of the patch, but declined rapidly near the edge. The concentrations of mannitol and glucose above both edges of the algal patch $(4-8 \mathrm{~mm}$ to the left, $8 \mathrm{~mm}$ to the right of center) were in the same range as water sampled above the mud surface well outside of the patch (16 mm left and right of center) (Fig. 5). Lower marker levels were measured above the left side of the study patch at distances of 2 and $4 \mathrm{~mm}$, compared with the right side of the patch; variable thickness of the algal mat or other differences that were not observed may explain the asymmetry in the release patterns for soluble compounds from this patch. Glucose and mannitol are thus spatially distinct markers of algal exudate, present in high concentrations immediately above the center of a given patch of $V$. longicaulis, but absent at the edges and over adjacent areas of the mudflat surface.

\section{Correlation of markers and bioactivity in water collected during a high tide}

The marker glucose was positively correlated with the bioactivity of water collected above algal patches during the first $30 \mathrm{~min}$ of a flood tide. To determine whether glucose was a useful marker during the subsequent hours of a high tide, water samples were collected $2 \mathrm{~h}$ after algal patches were submerged by a flood tide, when water depth was approximately $50 \mathrm{~cm}$. Samples were assayed for induction of larval metamorphosis and for glucose content as before. There was significant variation in the bioactivity of the water samples (Fig. 6, and results of a 1-way ANOVA: $\left.F_{8,18}=4.71, \mathrm{p}<0.005\right)$. Water collected above one patch induced significantly more metamorphosis than sea water controls and the least-active sample of field water (Scheffé test, p < 0.05). A significant concentration of the dissolved chemical settlement cue was thus present in water above certain Vaucheria longicaulis mats even during the peak of a high tide. The source of the variation between patches was likely a combination of varying thickness of different algal mats, and local hydrodynamics affecting dilution and distribution

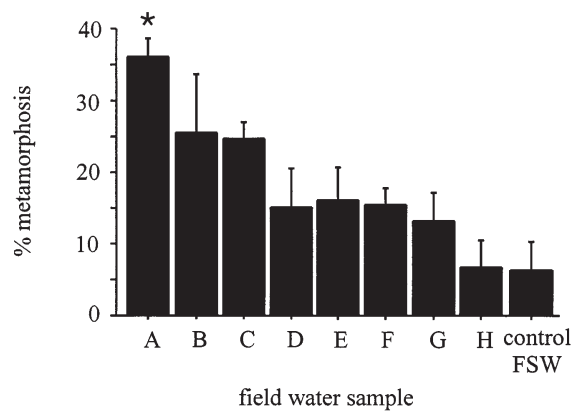

Fig. 6. Bioactivity of water collected above 8 distinct patches (labeled A to $\mathrm{H}_{i}$ FSW: filtered sea water) of Vaucheria longicaulis during the peak of a high tide, $2 \mathrm{~h}$ after tidal immersion. Data are mean percentages of larval metamorphosis (+SE) in response to a $3 \mathrm{~d}$ exposure to the indicated water sample. Arcsine-transformed percentages were compared using a 1-way ANOVA with a post-hoc Scheffé test $\left({ }^{*} \mathrm{p}<0.05\right.$ compared with sea water controls) 
of the dissolved cue. The significantly active sample also contained the highest concentration of glucose $(0.6 \mu \mathrm{M})$, and the concentration of glucose was significantly correlated with bioactivity for the overall data set (Spearman's rank correlation: $\rho=0.73, Z=2.07, \mathrm{p}<$ 0.05).

\section{Specificity of markers and bioactivity in Vaucheria longicaulis pore water}

The macroalga Enteromorpha clathrata sometimes co-occurs with Vaucheria longicaulis, and may cover the majority of the mudflat surface at certain times of the year at the Mission Bay field site. To determine whether the carbohydrate markers and bioactivity were specific to water conditioned by mats of $V$. longicaulis, water samples were collected from a small pool containing filamentous mats of E. clathrata; this E. clathrata pore water was tested for bioactivity in metamorphosis and behavioral assays, as well as for mannitol and glucose content. Results were compared with the sample of sea water collected $2 \mathrm{~mm}$ above a patch of $V$. longicaulis immediately upon tidal immersion (time 0; see Fig. 4A). There was significant variation in the percentage of metamorphosis induced by water collected above $V$. longicaulis, water trapped in mats of E. clathrata, and control sea water (Fig. 7A, and results of a 1 -way ANOVA: $F_{2,12}=25.30, \mathrm{p}<0.0001$ ). Water collected above $V$. longicaulis induced a significantly higher percentage of metamorphosis than did pore water from E. clathrata or a filtered sea water control (Scheffé test, $\mathrm{p}<0.001)$. Significant variation was also seen in the behavioral assay (Fig. 7B, and results of a 1way ANOVA: $\left.F_{2,198}=12.36, \mathrm{p}<0.0001\right)$. Water collected above $V$. longicaulis induced larvae to turn significantly more frequently than did E. clathrata pore water or control sea water (Scheffé test, p < 0.005).

The carbohydrate marker content was determined for 2 separate collections of pore water from Enteromorpha clathrata. Markers were identified in trace amounts, near the limits of detection of HPAEC-PAD, for both samples of E. clathrata pore water. In water collected among filaments of E. clathrata growing in a shallow pool, mannitol was present at a concentration of $0.44 \mu \mathrm{M}$ and glucose at $0.22 \mu \mathrm{M}$; water trapped within a damp, air-exposed mat of E. clathrata contained $0.13 \mu \mathrm{M}$ mannitol and $0.12 \mu \mathrm{M}$ glucose. These concentrations, close to background levels for Mission Bay water, were 1 order of magnitude below the levels of both markers detected in water collected $2 \mathrm{~mm}$ above a patch of Vaucheria longicaulis on the same day, and were 1 to 3 orders of magnitude lower than concentrations found in pore water collected within mats of $V$. longicaulis (Table 1). High levels of markers
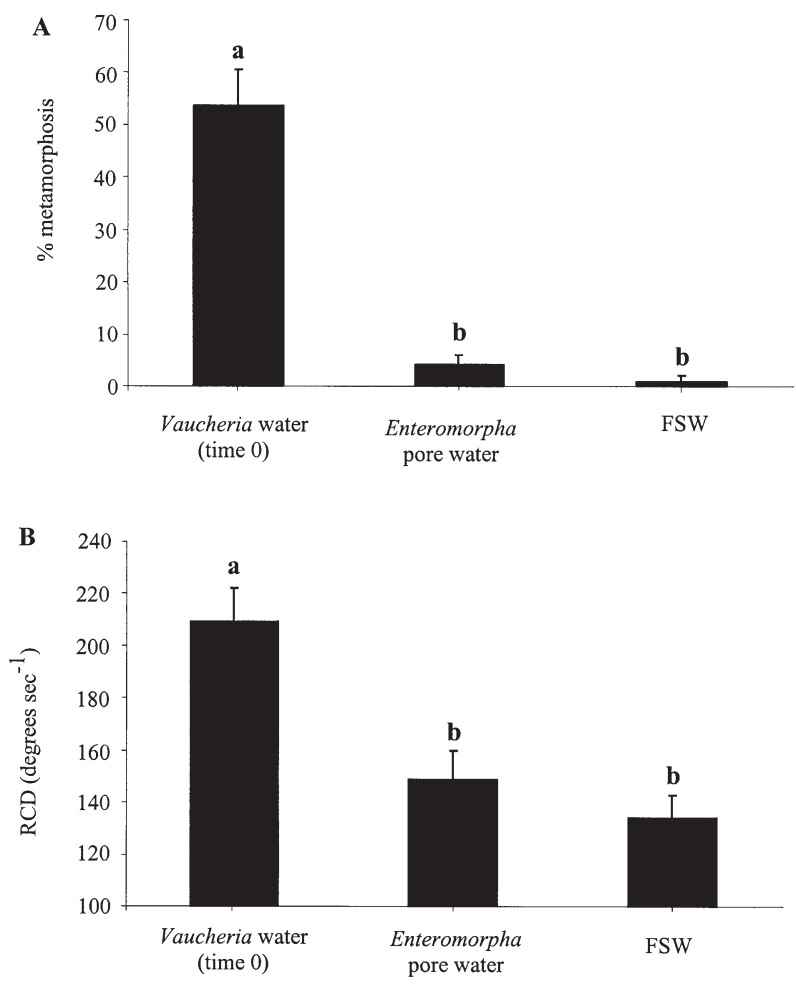

Fig. 7. Specificity of larval response to exudate from Vaucheria longicaulis. (A) Larval metamorphosis in response to water collected above a patch of $V$. longicaulis, water sampled from a pool densely packed with filaments of the macroalga Enteromorpha clathrata, and control filtered sea water (FSW). Vaucheria-conditioned water was collected above a mat of the algae immediately following immersion by a flood tide (time 0 sample). Data are mean $(+\mathrm{SE})$ percentages of metamorphosis. Means marked with the same letter did not differ significantly (1-way ANOVA on arcsine-transformed percentages, followed by a post-hoc Scheffé test). (B) Behavioral response of larvae to water conditioned by $V$. longicaulis, E. clathrata, or control FSW. Rate of change in direction (RCD) was quantified using motion analysis for larvae added to each of the water treatments in (A). Data are mean (+SE) RCD values. Means marked with the same letter did not differ significantly (1-way ANOVA followed by a post-hoc Scheffé test)

and bioactivity are therefore specific to pore water from patches of $V$. longicaulis, and are not present above background levels in pore water collected from mats of E. clathrata.

\section{DISCUSSION}

\section{Natural markers for tracing complex settlement cues in the field}

Despite decades of research, no structure has been published for any natural, water-soluble inducer of 
larval metamorphosis (Pawlik 1992). Limitations of analytical chemistry make it difficult, if not impossible, to identify trace amounts of polar metabolites in dilute sea water samples, confounding the isolation of dissolved cues (Zimmer-Faust \& Tamburri 1994). This is particularly true for carbohydrates, where separation and detection both present technical challenges (Krug 1998a). Thus, there have been no reports to date quantifying the release of any natural chemical cue for larval settlement, or tracing the distribution of soluble cues in the water column. While continuing to work towards identifying the structures of the complex carbohydrates responsible for the bioactivity of Vaucheria longicaulis pore water, we aimed to identify detectable markers with chemical and physical properties similar to the bioactive compounds. By quantifying production and release of such markers in the field, we sought to determine the distribution of the dissolved cue under natural conditions without direct detection of the cue itself. This study focused on the production of mannitol and glucose by $V$. longicaulis, 2 simple carbohydrates that are abundant in algal tissue but contain no intrinsic bioactivity in larval assays (Krug 1998a).

Glucose and its isomer fructose are the major free monosaccharides in sea water (Mopper et al. 1980, Ittekkot et al. 1981). Reported concentrations of glucose from different oceans ranged from $0.03 \mu \mathrm{M}$ to $0.67 \mu \mathrm{M}$, with a mean of approximately $0.3 \mu \mathrm{M}$ (Mopper et al. 1980); a similar mean value can be approximated from the data of Ittekkot et al. (1981). The background concentration of free glucose in Mission Bay water was measured at $0.1 \mu \mathrm{M}$ or less in the present study; concentrations of glucose in Vaucheria longicaulis pore water were thus 1 to 3 orders of magnitude above background levels in Mission Bay. The free sugar alcohol mannitol, a reduced form of mannose, has not been reported as a major free carbohydrate component of sea water samples, and was not detectable in Mission Bay water. The high concentration of mannitol in $V$. longicaulis pore water (nearly $\mathrm{mM}$ in some patches) is thus a clear indicator of water that has been trapped within an algal mat. Mannitol is the predominant low molecular weight carbohydrate contained in tissue of $V$. longicaulis, representing $1.5 \%$ of the dry mass of the algae (Krug 1998a). The consistent mean 4.3 ratio of mannitol to glucose in pore water averaged across several patches, regardless of the absolute concentrations of the 2 markers, appears to be a distinctive chemical signature of the algae, and may be a diagnostic feature of $V$. longicaulis-conditioned sea water in the field.

In samples taken above one Vaucheria longicaulis mat, the mannitol signature of diffusing pore water was evident at time 0 , but rapidly diminished over the first 5 min of the flood tide to near-background levels. In contrast, elevated levels of glucose were apparent in water above the algal patch for the first 20 to $30 \mathrm{~min}$ of the flood tide. This discrepancy may be due to different sources for the 2 markers. Mannitol is a fully reduced sugar alcohol with no reducing end, and cannot be polymerized into oligosaccharides; all mannitol is therefore located intracellularly within V. longicaulis tissue. The high levels of mannitol measured in laboratory production experiments and in field samples of pore water are most likely due to cell lysis or leakage of cellular contents. $V$. longicaulis is a siphonaceous alga, with a continuous cytoplasm inside each filament (Abbott \& Hollenberg 1976); damage to the algae could lead to considerable leakage of intracellular products into the surrounding medium. In the field, feeding by adult specimens of Alderia modesta may damage algal blades and contribute to the subsequent leakage of mannitol into pore water. Adult slugs feed by puncturing the algal cell wall and then sucking out the cytoplasm; damaged thalli may continue to leak mannitol until wound healing occurs (Tornbom \& Oliveira 1993a,b). In contrast, glucose exists both as the most abundant free monosaccharide inside the cytoplasm and also as the major component of both soluble oligosaccharides and cell wall polysaccharides of the alga (Krug 1998a). The continuous sloughing off of cell-surface polysaccharides and subsequent microbial degradation will contribute to the glucose concentration of $V$. longicaulis pore water. This may explain why the glucose signature of pore water persists in the overlying water column for much longer periods than mannitol, even during later hours of a high tide: glucose can be continually released from the surface of the algal tissue through degradation of glucose-containing polymers, whereas mannitol can only accumulate during low tides as a product of cell leakage.

The results demonstrate that even when the chemical structure of a settlement cue is unknown, more easily detectable compounds may be useful as proxy molecules for field research. To our knowledge, this is the first use of natural markers to track the release and transport of active compounds from a benthic source into the water column. Additional research is needed to examine the release of dissolved compounds from replicate patches of algae in different seasons, to fully characterize how these processes function in the natural habitat. This study serves as a proof of the concept that natural markers can be a useful tool for understanding how polar molecules are distributed in the field. Furthermore, these compounds provide insight into the natural rates of production by the algae and subsequent dilution of waterborne cues by local hydrodynamic forces. 


\section{Role of dissolved cues: settlement in the field}

The results demonstrate that water-soluble chemical cues from the alga Vaucheria longicaulis accumulate in pore water during low tides, and are subsequently released in a concentrated burst when patches of the algae are initially immersed by the next flood tide. Both marker concentration and bioassay data indicated that the soluble cue was largely diluted by rising tidal waters within 10 min of immersion, and reached background levels within $30 \mathrm{~min}$ for the patch analyzed in Fig. 4. However, 1 out of 8 patches (Fig. 6) still released a significant amount of glucose and the dissolved cue during the second hour of a high tide, suggesting that some algal mats may continue to release carbohydrates well into a given tidal cycle. These results may have important implications for the settlement of larvae of Alderia modesta in the field. If dissolved cues are important in mediating settlement in this species, larvae carried over the algal patches during the first few minutes of a high tide should have a greater chance of settling in response to waterborne cues than larvae that are transported over patches later in a high tide.

Future work will involve determining whether larvae 'ride' the front of the rising tide, which would result in the maximum exposure to dissolved settlement cues. Both long- and short-lived larvae of Alderia modesta showed immediate and dramatic changes in swimming behavior in response to the soluble cue (Krug \& Zimmer 2000). Such swimming behaviors would have the best chance of increasing settlement under conditions of slow water flow. We have begun to characterize the hydrodynamic environment of settling larvae, using acoustic Doppler velocimetry to measure flow in 3 dimensions over patches of Vaucheria longicaulis in the field. The mean velocity $1 \mathrm{~cm}$ over a patch of algae during the first $100 \mathrm{~min}$ of a high tide was $1.13 \mathrm{~cm} \mathrm{~s}^{-1}$, and the mean $u_{*}$ value during this time interval was $0.19 \mathrm{~cm} \mathrm{~s}^{-1}$ (authors' unpubl. data). These results indicate that the back bay habitat in which larvae of $A$. modesta settle is characterized by very slow flow and low turbulence, conditions which should enable larvae to respond to dissolved cues and increase their chance of successful settlement onto an algal patch. Further field work will indicate how biology, chemistry, and physics interact to mediate settlement during the initial period of each flood tide, as predicted from the present data.

To fully characterize the distribution of waterborne cues in the field, we are expanding this study by sampling above replicate patches of Vaucheria longicaulis, at various heights in the water column and at multiple distances from the centers of different algal mats. By combining marker concentration profiles with bioassay data, it will be possible to estimate production and flux out of algal mats; measurement of hydrodynamic forces such as turbulent mixing over algal mats will contribute to our understanding of how transport of the dissolved settlement cue occurs over both space and time. The ultimate goal is to determine where in the mudflat habitat, and during what times in a tidal cycle, soluble cues may influence patterns of larval settlement. Larval collectors can then be used to release known amounts of the dissolved algal compounds, to demonstrate larval availability and response to soluble cues in the field. In a previous study, collectors were engineered to release inductive and non-inductive peptide cues from acrylamide gels, over time at a controlled and monitored rate; release of the inductive cue at trace concentrations significantly enhanced settlement of barnacle cyprids in the field (Browne \& Zimmer unpubl. results). Using a similar approach, our aim is to release the dissolved cue from $V$. longicaulis at different places and times during a tidal cycle, to quantify the settlement response of larvae under natural conditions.

To our knowledge, this is the first report to suggest that patterns of settlement in an intertidal habitat may vary widely over a short time frame, due to dilution of waterborne cues during a rising tide. Similar situations may exist for larvae of other species which settle on mudflats and in estuarine environments, as well as in rocky intertidal habitats where cues could accumulate in isolated tide pools and disperse during flood tides. Even in rocky subtidal or coral reef environments, chemical cues could accumulate in areas of low flow speed and low turbulent mixing, such as within crevices, dense kelp beds, or coral heads. The current study thus demonstrates the value of the marker approach, highlighting a potentially important ecological phenomenon that might be overlooked if the chemistry of dissolved molecules and the physics of the environment were not taken into account. By combining studies of the behavior of organisms, the distribution of signal molecules, and the hydrodynamics of field habitats, it may ultimately be possible to define the role of dissolved compounds in mediating complex processes such as larval settlement in the marine environment.

Acknowledgements. This research was sponsored by an award from the Sea Grant College Program (R/CZ-152) through the National Marine Biotechnology Initiative. Access to the study site was provided by the Natural Reserve Office of the University of California, and we thank Isabelle Kay for facilitating field access.

\section{LITERATURE CITED}

Abbott IA, Hollenberg GJ (1976) Marine algae of California. Stanford University Press, Stanford

Bleakney JS, Bailey KH (1967) Rediscovery of the salt-marsh 
ascoglossan Alderia modesta Lovén in eastern Canada. Proc Malacol Soc Lond 37:347-349

Butman CA (1987) Larval settlement of soft-sediment invertebrates: the spatial scales of pattern explained by habitat selection and the emerging role of hydrodynamic processes. Oceanogr Mar Biol Annu Rev 25:113-165

Day RW, Quinn GP (1989) Comparisons of treatments after an analysis of variance in ecology. Ecol Monogr 59:433-463

den Hartog C, Swennen C (1952) On the occurrence of Alderia modesta (Lovæn) and Limapontia depressa $\mathrm{A}$. and $\mathrm{H}$. on the salt marshes of the Dutch Wadden Sea. Beaufortia $2: 1-3$

Eckman JE, Werner FE, Gross TF (1994) Modelling some effects of behavior on larval settlement in a turbulent boundary layer. Deep-Sea Res II 41:185-208

Gleeson RA, Adams MA, Smith AB (1984) Characterization of a sex pheromone in the blue crab, Callinectes sapidus: crustecdysone studies. J Chem Ecol 10:913-921

Grahame J, Branch GM (1985) Reproductive patterns of marine invertebrates. Oceanogr Mar Biol Annu Rev 23:373-398

Grosberg R (1982) Intertidal zonation of barnacles: the influence of planktonic zonation of larvae on the vertical distribution of adults. Ecology 63:894-899

Hadfield MG, Scheuer D (1985) Evidence for a soluble metamorphic inducer in Phestilla: ecological, chemical and biological data. Bull Mar Sci 37:556-566

Hay ME (1996) Marine chemical ecology: what's known and what's next? J Exp Mar Biol Ecol 200:103-134

Ittekkot V, Brockmann U, Michaelis W, Degens E (1981) Dissolved free and combined carbohydrates during a phytoplankton bloom in the northern North Sea. Mar Ecol Prog Ser 4:299-305

Kerhervé P, Charrière P, Gadel F (1995) Determination of marine monosaccharides by high-pH anion exchange chromatography with pulsed amperometric detection. J Chromatogr A718:283-289

Krug PJ (1998a) Chemical and larval ecology of opisthobranch molluscs: variable development modes and settlement requirements for larvae of Alderia modesta. $\mathrm{PhD}$ dissertation, University of California, San Diego

Krug PJ (1998b) Poecilogony in an estuarine opisthobranch: planktotrophy, lecithotrophy, and mixed clutches in a population of the ascoglossan Alderia modesta. Mar Biol 132: 483-494

Krug PJ (in press) Bet-hedging dispersal strategy of a specialist marine herbivore: a settlement dimorphism among sibling larvae of Alderia modesta. Mar Ecol Prog Ser

Krug PJ, Manzi AE (1999) Waterborne and surface-associated carbohydrates as settlement cues for larvae of the specialist marine herbivore Alderia modesta. Biol Bull 197: 94-103

Krug PJ, Zimmer RK (2000) Developmental dimorphism and expression of chemosensory-mediated behavior: habitat selection by a specialist marine herbivore. J Exp Biol 203: 1741-1754

Lambert WJ, Todd CD (1994) Evidence for a water-borne cue inducing metamorphosis in the dorid nudibranch mollusc Adalaria proxima (Gastropoda: Nudibranchia). Mar Biol 120:265-271

Editorial responsibility: Joseph Pawlik (Contributing Editor), Wilmington, North Carolina, USA
Leonard GH, Bertness MD, Yund PO (1999) Crab predation, waterborne cues, and inducible defenses in the blue mussel, Mytilus edulis. Ecology 80:1-14

Levin LA (1982) The roles of life history, dispersal and interference competition in the population and community structure of a dense infaunal polychaete assemblage. $\mathrm{PhD}$ dissertation, University of California, San Diego

Levin LA (1984) Life history and dispersal patterns in a dense infaunal polychaete assemblage: community structure and response to disturbance. Ecology 65:1185-1200

Levin LA, Bridges TS (1995) Pattern and diversity in reproduction and development. In: McEdward LR (ed) Ecology of marine invertebrate larvae. CRC Press, Boca Raton, FL, p $1-47$

Mopper K, Dawson R, Liebezeit G, Ittekkot V (1980) The monosaccharide composition of natural waters. Mar Chem 10:55-66

Pawlik JR (1992) Chemical ecology of the settlement of benthic marine invertebrates. Oceanogr Mar Biol Annu Rev 30:273-335

Pawlik JR, Butman CA, Starczak VR (1991) Hydrodynamic facilitation of gregarious settlement of a reef-building tube worm. Science 251:421-424

Roughgarden J, Gaines S, Possingham H (1988) Recruitment dynamics in complex life cycles. Science 241:1460-1466

Snedecor GW, Cochran WG (1980) Statistical methods, 7th edn. Iowa State University Press, Ames

Sokal RR, Rohlf FJ (1981) Biometry: the principle and practice of statistics in biological research 2nd edn. WH Freeman and $\mathrm{Co}$, New York

Strathmann RR (1990) Why life histories evolve differently in the sea. Am Zool 30:197-207

Tamburri MN, Finelli CM, Wethey DS, Zimmer-Faust RK (1996) Chemical induction of larval settlement behavior in flow. Biol Bull 191:367-373

Tornbom L, Oliveira L (1993a) Wound-healing in Vaucheria longicaulis var. macounii Blum.: 1. Cytomorphological study of the wound response. New Phytol 124:121-133

Tornbom L, Oliveira L (1993b) Wound-healing in Vaucheria longicaulis var. macounii Blum.: 2. Cytoplasmic streaming and organelle movement. New Phytol 124:135-148

Trowbridge C (1993) Local and regional abundance patterns of the ascoglossan opisthobranch Alderia modesta (Lovén, 1844) in the Northeastern Pacific. Veliger 36:303-310

Turner EJ, Zimmer-Faust RK, Palmer MA, Luckenback M (1994) Settlement of oyster (Crassostrea virginica) larvae: effects of water flow and a water-soluble chemical cue. Limnol Oceanogr 39:1579-1593

Underwood AJ, Fairweather PG (1989) Supply-side ecology and benthic marine assemblages. Trends Ecol Evol 4: $16-20$

Zimmer RK, Butman CA (2000) Chemical signaling processes in the marine environment. Biol Bull 198:168-187

Zimmer-Faust RK (1989) The relationship between chemoreception and foraging behavior in crustaceans. Limnol Oceanogr 34:1367-1374

Zimmer-Faust RK, Tamburri MN (1994) Chemical identity and ecological implications of a waterborne, larval settlement cue. Limnol Oceanogr 39:1075-1087

Submitted: April 26, 2000; Accepted: August 15, 2000

Proofs received from author(s): October 11, 2000 